\title{
Dysbiosis in the Gut Microbiota of Soil Fauna Explains the Toxicity of Tire Tread Particles
}

\author{
Jing Ding, ${ }^{\bigcirc}$ Dong Zhu, ${ }^{\bigcirc}$ Hong-Tao Wang, Simon Bo Lassen, Qing-Lin Chen, Gang Li, Min Lv, \\ and Yong-Guan Zhu*
}

Cite This: Environ. Sci. Technol. 2020, 54, 7450-7460

Read Online

ACCESS | Lill Metrics \& More | 国 Article Recommendations ｜ st Supporting Information

ABSTRACT: Tread particles (TPs) from vehicle tires are widely distributed in soil ecosystems; therefore, there is an urgent need to evaluate their effects on soil biota. In the present study, the soil worm Enchytraeus crypticus was incubated for 21 days in soil microcosms containing increasing concentrations of TPs $(0,0.0048 \%, 0.024 \%, 0.12 \%, 0.6 \%$, and $3 \%$ of dry soil weight). High concentrations of zinc (Zn, $9407.4 \mathrm{mg} \mathrm{kg}^{-1}$ ) and polycyclic aromatic hydrocarbons (PAHs, 46.8 $\mathrm{mg} \mathrm{kg}^{-1}$ ) were detected in the TPs, which resulted in their increased concentrations in soils amended with TPs. We demonstrated that TPs had an adverse effect on the survival (decreased by more than 25\%) and reproduction (decreased by more than $50 \%$ ) of the soil worms. Moreover, TP exposure disturbed the microbiota of the worm guts and surrounding soil. In addition, a covariation between bacterial and fungal communities was observed in the worm guts after exposure to TPs. Further analysis showed that TP exposure caused an enrichment of microbial genera associated with opportunistic pathogenesis in the worm guts. The combined results from this study indicate that TPs might threaten the terrestrial ecosystem by affecting soil fauna and their gut microbiota.

\section{INTRODUCTION}

Plastics are ubiquitous in our daily life and widely used in consumer products and industry, leading to widespread pollution of microplastics (MPs). ${ }^{1}$ MPs have, however, been recognized as a serious global threat since they can affect both marine and terrestrial organisms, even the health of humans. $^{2-4}$ As a special class of plastics, tread particles (TPs) released from car and airplane tires have attracted far less attention so far. However, a global scale survey has demonstrated that great amounts of TPs are released into the environment, resulting in a total of 5917518 tons of TPs emitted per year. ${ }^{5}$ Moreover, TPs, which consist of rubber, filling agents, oil, vulcanization agents, and other additives, can release other contaminants such as heavy metals and polycyclic aromatic hydrocarbons (PAHs) into the environment. ${ }^{6,7}$ Therefore, TPs may be an emerging threat to ecosystems, and their ecotoxicological effects need urgent investigation.

Many studies have demonstrated that TPs induce adverse effects on aquatic organisms, mainly through physical damage. ${ }^{8}$ Wagner et al. (2018) conducted a review on the toxic effects of TPs in aquatic environments and concluded that the toxicity might be due to leaching of toxic compounds such as $\mathrm{Zn}^{6}{ }^{6}$ In these toxicology tests, the test organisms were exposed to leachates after the removal of TPs; and exposure led to a significant reduction in survival, ${ }^{9-11}$ further suggesting that TP-derived compounds are responsible for the high toxicity of TPs. ${ }^{12-15}$ Moreover, TP leachates treated with ion-exchange or solid-phase extraction (SPE) columns exhibited reduced toxicity, indicating that organic compounds such as PAHs contribute to the toxicity of TPs. ${ }^{11,16}$ Nevertheless, the mechanisms behind TP-inducted effects on the biota need further investigation.

While various studies have investigated the ecotoxicology of TPs in aquatic environments, limited studies have been conducted to investigate their effect on soil ecosystems, especially their toxicity to soil biota. ${ }^{6,7}$ It is estimated that $67 \%$ of all emitted TPs end up in soils by air and runoff transportation, while only 12,6 , and $15 \%$ end up in the air, surface waters, and sewers, respectively. ${ }^{5}$ The soil environment is, therefore, the most dominant reservoir for TPs, with concentrations ranging from 103 to $117000 \mathrm{mg} \mathrm{kg}$. Moreover, sewage sludge application can also contribute to the transportation of TPs into soils, as more than $60 \%$ of TPs remain in sewage sludge after wastewater treatment. ${ }^{17}$ TPs may, therefore, have a similar effect on soil biota, if not more, as they have on aquatic organisms, since the soil biota may be directly exposed to the TPs or TP leachates. ${ }^{18}$ Hence, there is no doubt that soil ecosystems have already suffered or will suffer from the heavy pollution of TPs and there is, thus, an

Received: February 13, 2020

Revised: April 5, 2020

Accepted: May 28, 2020

Published: May 28, 2020 
urgent need for evaluating their effects on the soil biota, particularly in urban environments.

Soil fauna is a key group of soil organisms, playing crucial roles in soil ecosystems such as litter decomposition and nutrients cycling. ${ }^{19-21}$ However, their guts may be directly exposed to TPs during soil ingestion, and TP leachates in soil may be assimilated by the soil fauna bodies. Hence, the effects of TPs on soil fauna may be a key link for investigating the threats of TP to terrestrial ecosystems. Furthermore, some species of soil fauna such as Folsomia candida and Enchytraeus crypticus (E.crypticus) are model species and are widely used in soil ecotoxicological studies. For example, some studies have tested the ecotoxicity of MPs in soil using Folsomia candida and E. crypticus, revealing that MP exposure can decrease their body weight and reproduction and even alter their isotope fractionation. $^{22,23}$ Additionally, some studies have strongly recommended that the gut microbiota of soil fauna must be considered to fully evaluate the toxicity of environmental contaminants as the gut microbiota contributes to the immunity and metabolism of its host and may be more sensitive to pollutants than the host itself. ${ }^{24,25}$ Both the bacterial and fungal communities in soil fauna guts play important roles in the health of the host. ${ }^{26,27}$ However, the effects of TPs on soil fauna have never been investigated. Moreover, the responses and nexus of the bacterial and fungal communities in the guts of soil fauna after exposure to soil contaminants are still elusive.

In the present study, a standardized ecotoxicological experiment was conducted to evaluate the effects of TPs on the soil worm E. crypticus, which we previously have used to evaluate the effects of nanoplastics on soil biota. ${ }^{22}$ Moreover, for the first time, the effects of TPs on both the bacterial and fungal communities of the guts of soil fauna were investigated. The effects were assessed by exposing the soil fauna to a wide range of environmentally relevant concentrations of TPs. The aims of the study were as follows: (1) to determine the concentrations of heavy metals and PAHs in TPs and soils amended with TPs; (2) to investigate changes in the survival and reproduction of soil fauna during TP exposure; (3) to assess the response of the gut and soil microbiota to different TP concentrations; and (4) to reveal the responses and nexus between bacterial and fungal communities in the soil fauna guts after TP exposure.

\section{MATERIALS AND METHODS}

Preparation of Car Tire TPs. To simulate an environmentally relevant scenario of TP exposure, a second-hand car tire (SUNFULL, China, all season, sidewall markings: 155R12C 8PR 88/86Q) was collected from a garage in Xiamen, China. The TPs were generated from the surface of the car tire using a stainless-steel grater. ${ }^{28}$ After, the TPs were sieved through a $500 \mu \mathrm{m}$ mesh to remove large size particles (Figure S1 of the Supporting Information, SI). ${ }^{28}$ The particle size of the remaining TPs ranged from $13 \mu \mathrm{m}$ to $1,400 \mu \mathrm{m}$ with a medium diameter of $225.6 \mu \mathrm{m}$ (Figure S2), as determined by a Mastersizer 2000 (Malvern Instruments, U.K.).

Test Soil and Organisms. Soil (Fluvo-aquic soil) was collected from a vegetable field located in Ningbo China $\left(29.49^{\circ} \mathrm{N}, 121.17^{\circ} \mathrm{E}\right)$, far from highways and with no known history of sludge amendment. The total carbon content and nitrogen content of the acid soil (with a $\mathrm{pH}$ of 4.94) was 246.2 $\mathrm{mg} \mathrm{kg}^{-1}$ and $23.4 \mathrm{mg} \mathrm{kg}^{-1}$, respectively. The sampled soil was air-dried, defaunated by heating at $80{ }^{\circ} \mathrm{C}$ for $24 \mathrm{~h}$, and sieved through a $2 \mathrm{~mm}$ nylon sieves. The soil worm, E. crypticus, was obtained from Aarhus University in Denmark and has been cultured in a standard medium $\left(2 \mathrm{mmol} \mathrm{CaCl}_{2}, 1 \mathrm{mmol}\right.$ $\mathrm{MgSO}_{4}, 1 \mathrm{mmol} \mathrm{NaHCO}$ in $27 \mathrm{~g}$ agarose $\mathrm{L}^{-1}$ with $\mathrm{pH} 7.8$ ) and fed with oatmeal (Pepsi Food Co., Beijing, China) for over two years in our laboratory following the OECD guidelines $(2004){ }^{29}$

Experimental Design. A microcosm experiment was conducted to reveal the effects of TPs on the soil fauna and their gut microbiota. TPs were added and homogenized to five equal amounts of soil (120 $\mathrm{g}$ of dry soil) at a dose of $0.0048 \%$, $0.024 \%, 0.12 \%, 0.6 \%$, and $3 \%(\mathrm{w} / \mathrm{w})$, respectively. The doses of TPs were within the range of reported concentrations of TPs in soils. ${ }^{7}$ An additional $120 \mathrm{~g}$ of untreated, dry soil was used as control treatment with no TP amendment. More than $20 \mathrm{~g}$ sterilized water was added to each treatment to adjust the water content to $60 \%$ of the initial water holding capacity of the soil. Each microcosm consisted of a $100 \mathrm{~mL}$ glass beaker filled with $35 \mathrm{~g}$ of the relevant soil-TP mixture. Four replicas of each soil-TP mixture were included in the present study, resulting in a total of 24 microcosms. Prior to the start of the experiment, microcosms were preincubated for 2 weeks to stabilize the soil properties. Afterward, 10 sexually mature $E$. crypticus (with a band) were randomly selected and added into each microcosm according to the OECD guidelines (2004). ${ }^{29}$ All the microcosms were incubated for 3 weeks in the same condition as the preincubation at $20 \pm 1{ }^{\circ} \mathrm{C}$ with a relative humidity of $75 \%$ and an $8: 16$ light/dark cycle. The juvenile worms could not reach sexual maturity during the exposure period. Sterilized water was added to the microcosms each week to maintain the water content during the entire incubation period.

Analysis of Survival and Reproduction Rate. The numbers of the living adult and juvenile worms were used to represent the survival and reproduction rate of the microcosms. The adult worms in each microcosm were separated from the soil and counted. Before counting the juveniles, $3 \mathrm{~g}$ of fresh soil without visible worms was collected for analysis of the soil microbiota, as well as heavy metal and PAH content. To better count the juveniles, they were killed, fixed, and dyed by adding ethanol $(1 \mathrm{~mL})$ and a Bengal rose solution $(300 \mathrm{uL}$, $1 \%)$, respectively. Afterward, $50 \mathrm{~mL}$ of distilled water was added to each beaker, gently stirred, and left for $6 \mathrm{~h}$ at $4{ }^{\circ} \mathrm{C}$. The juveniles were isolated from the suspension by sieving through a $0.15 \mathrm{~mm}$ sieve and were counted on a photo using the ImageJ software (2006 version, National Institute of Health, U.S.A.).

Analysis of Heavy Metals and PAHs in the TPs and Soil-TP Mixtures. For each replicated microcosm, $2.5 \mathrm{~g}$ of the collected fresh soil was freeze-dried and grinded for heavy metal and PAHs analysis. The total amount of heavy metals, including $\mathrm{As}, \mathrm{Cd}, \mathrm{Cr}, \mathrm{Ni}, \mathrm{Zn}$, and $\mathrm{Pb}$ (high amounts of these metals in TPs have been reported in previous studies ${ }^{6}$ ), in the TPs and soil-TP mixtures, were analyzed using ICP-MS after microwave digestion with $\mathrm{HNO}_{3}-\mathrm{HCL}$. In addition, Soxhlet extraction was used to extract the PAHs in the TPs and soilTP mixtures, and the concentration of 16 PAHs were determined using a GC-MS, according to Sadiktsis et al. (2012). ${ }^{16}$

DNA Extraction of the Gut and Soil Microbiota. Five adult worms from each microcosm were randomly selected and killed in ethyl alcohol. Their heads were removed with a sterilized blade after five times of washing with sterilized PBS, 
Table 1. Concentrations of Heavy Metals and PAHs in Tread Particles (TPs)

$\begin{array}{cccccc}\text { heavy metals } & \text { As } & \mathrm{Cd} & \mathrm{Cr} & \mathrm{Cu} & \mathrm{Ni} \\ \text { concentration }\left(\mathrm{mg} \mathrm{kg}^{-1}\right) & 63.3 & 1.1 & 63.3 & 98.6 & 42.9 \\ \text { PAHs } & \text { two-ring } & \text { three-ring } & \text { four-ring } & \text { five-ring } & \text { six-ring } \\ \text { concentration }\left(\mathrm{mg} \mathrm{kg}^{-1}\right) & 0.5 & 1.6 & 30.3 & 9.1 & 5.3\end{array}$

which could remove the soil and microbiota from the body surface. The residual bodies were then transferred into a $2 \mathrm{~mL}$ Eppendorf tube, and the DNA was extracted using a DNeasy Blood and Tissue Kit (Qiagen, Hilden, Germany). Considering that it was difficult to isolate the gut from the worm body and most microorganisms existed in the worm gut, the whole body was used to extract DNA to represent their gut microbiota. ${ }^{22,30}$ The detailed procedure for DNA extraction has been described previously. ${ }^{31}$ The residual collected fresh soil from each microcosm was used for DNA extraction using a DNeasy Powersoil Kit (Qiagen, Hilden, Germany) following the manufacturer's protocol. The obtained DNA was kept at $-20{ }^{\circ} \mathrm{C}$ until further use.

Characterization of the Gut and Soil Microbiota. Illumina sequencing was used to characterize the bacterial and fungal communities in the soil and worm guts. Barcoded $515 F / 806 \mathrm{R}$ and gITS7/ITS4 primers were used to amplify the $\mathrm{V} 4$ region of the bacterial $16 \mathrm{~S}$ rRNA gene and the fungal ITS2 region, respectively. ${ }^{30,32}$ The amplification was conducted in a $50 \mu \mathrm{L}$ reaction system containing $25 \mu \mathrm{L}$ TaKaRa ExTap, $1 \mu \mathrm{L}$ DNA, $2 \mu \mathrm{L}$ corresponding forward and backward primer, and $22 \mu \mathrm{L}$ of PCR-grade water. The PCR was conducted in triplicate for each sample, and amplification of the bacterial V4 regions was conducted at $95{ }^{\circ} \mathrm{C}$ for $5 \mathrm{~min}$, followed by 30 cycles of $94{ }^{\circ} \mathrm{C}$ for $45 \mathrm{~s}, 50{ }^{\circ} \mathrm{C}$ for $45 \mathrm{~s}, 68{ }^{\circ} \mathrm{C}$ for $45 \mathrm{~s}$, and a final step at $72{ }^{\circ} \mathrm{C}$ for $10 \mathrm{~min}$. Amplification of the fungal ITS2 regions was conducted at $95{ }^{\circ} \mathrm{C}$ for $15 \mathrm{~min}$, followed by 30 cycles of $95{ }^{\circ} \mathrm{C}$ for $30 \mathrm{~s}, 56{ }^{\circ} \mathrm{C}$ for $30 \mathrm{~s}, 72{ }^{\circ} \mathrm{C}$ for $60 \mathrm{~s}$, and a final step at $72{ }^{\circ} \mathrm{C}$ for $10 \mathrm{~min}$. The PCR products were purified, pooled at the same concentration, and then sequenced using an Illumina Hiseq2500 platform (Novogene, Beijing, China).

QIIME was used to analyze the high-throughput sequencing data according to the online instructions. ${ }^{33}$ The data analysis process was conducted following the methods of our previous studies. ${ }^{34}$ Briefly, clean reads were obtained by filtering adaptor sequences and removing low-quality reads, ambiguous nucleotides, and barcodes. The operational taxonomic units (OTUs) were identified at a $3 \%$ sequence difference. ${ }^{35}$ Taxonomy classification was assigned using UCLUST against the Ribosomal Database Project (RDP) database (version 11.5) for bacteria ${ }^{36}$ and by using BLAST against the UNITE database (version 7.2) for fungi. ${ }^{39}$ Singletons were removed for downstream analysis. The Shannon index was calculated to reveal the alpha-diversity of the microbiota, and principal coordinate analysis (PCoA) based on the Bray-Curtis distance was conducted to investigate the beta-diversity.

Statistical Analysis. One-way ANOVA $(P<0.05)$ combined with the Tukey HSD test was applied to determine the effects of TPs on heavy metal and PAH concentrations in the soils, the survival and reproduction of the worms, and the microbial diversity in the soil and worm guts. The independent $t$-test was conducted to compare differences between the soil and gut microbiota in regards to microbial diversity and abundant taxa. Regression analyses were conducted to evaluate the potential relationships between gut microbiota (which was standardized by the first axis of PCoA) and survival and reproduction rates of worms. One-way ANOVA, the independent $t$-test and regression analyses were conducted using SPSS software (version 20, SPSS Inc., Chicago, U.S.A.). Both the Adonis and the Anosim test with 999 permutations were used to statistically evaluate the effects of TPs on the microbial community structure of the worm guts and soil. Differences between treatments were compared according to Bray-Curtis dissimilarity metrics. Procrustes test and the Mantel test were applied to depict the covariation of the bacterial and fungal communities in the worms gut after TP exposure. Co-occurrence patterns between the bacterial and fungal communities were revealed by a network analysis using $\mathrm{R}$ (Version 3.4.1). The Adonis, Anosim, Mantel, and Procrustes tests were conducted using R (Version 3.4.1). A heatmap was used to display the relative abundance of the most abundant bacterial and fungal OTUs in the worm guts and soil.

\section{RESULTS}

Heavy Metal and PAH Concentrations in TPs and TPAmended Soils. Heavy metals, including As, Cd, Cr, Cu, Ni, $\mathrm{Zn}$, and $\mathrm{Pb}$, were detected in the TPs at concentrations ranging between $1.1 \mathrm{mg} \mathrm{kg}^{-1}$ and $9407.4 \mathrm{mg} \mathrm{kg}^{-1}$ (Table 1). The most abundant heavy metal in the TPs was $\mathrm{Zn}$, corresponding to $0.94 \%$ of the TP dry weight (Table 1 ). Sixteen subtypes of PAHs were, in addition, quantified in the TPs, with the most abundant being pyrene $\left(11.6 \mathrm{mg} \mathrm{kg}^{-1}\right)$, benz[a] anthracene (4.8 $\left.\mathrm{mg} \mathrm{kg}^{-1}\right)$, chrysene $\left(11.5 \mathrm{mg} \mathrm{kg}^{-1}\right)$, and benzo[b]fluoranthene $\left(3.4 \mathrm{mg} \mathrm{kg}^{-1}\right)$. The total PAH content was 46.5 $\mathrm{mg} \mathrm{kg}^{-1}$ of TP. The 4-ring and 5-ring PAHs were the most predominant congeners, accounting for $65.1 \%$ and $19.6 \%$ of the total PAHs, respectively (Table 1 ).

The concentration of heavy metals in the soil-TP mixtures did not vary between treatments, except for $\mathrm{Zn}$ (Table S1), where a significant linear correlation between TP content and total $\mathrm{Zn}$ content was observed $\left(R^{2}=0.94, P<0.001\right.$, Figure S3). Amendment with TPs significantly increased the concentrations of eight types of PAHs in the soil-TP mixtures, especially in the highest TP treatment (3\%) (Table S1). Except for anthracene, the other seven types of PAH concentrations were linearly correlated with the TP content of the soil-TP mixtures (Figure S4).

Effects of TPs on the Survival and Reproduction Rate of Worms. There was a significant decrease in the survival rate of worms exposed to TP concentrations above $0.024 \%(P<$ 0.05 , Figure 1a), compared to the control treatment. Moreover, a dose-dependent effect of TPs on the reproduction rate of the worms was observed (Figure 1b). The concentration of TPs in the mixtures was logarithmically correlated with the number of juvenile worms $\left(R^{2}=0.50, P<\right.$ 0.001 , Figure S5), which was reduced by $12.0 \%, 20.1 \%, 26.2 \%$, $42.8 \%$, and $50.8 \%$ for the TP exposures of $0.0048 \%, 0.024 \%$, $0.12 \%, 0.6 \%$, and $3 \%$, respectively (Figure $1 \mathrm{~b}$ ).

Effects of TP Exposure on the Soil and Gut Microbial Community. After quality filtering, a total of 3348760 and 


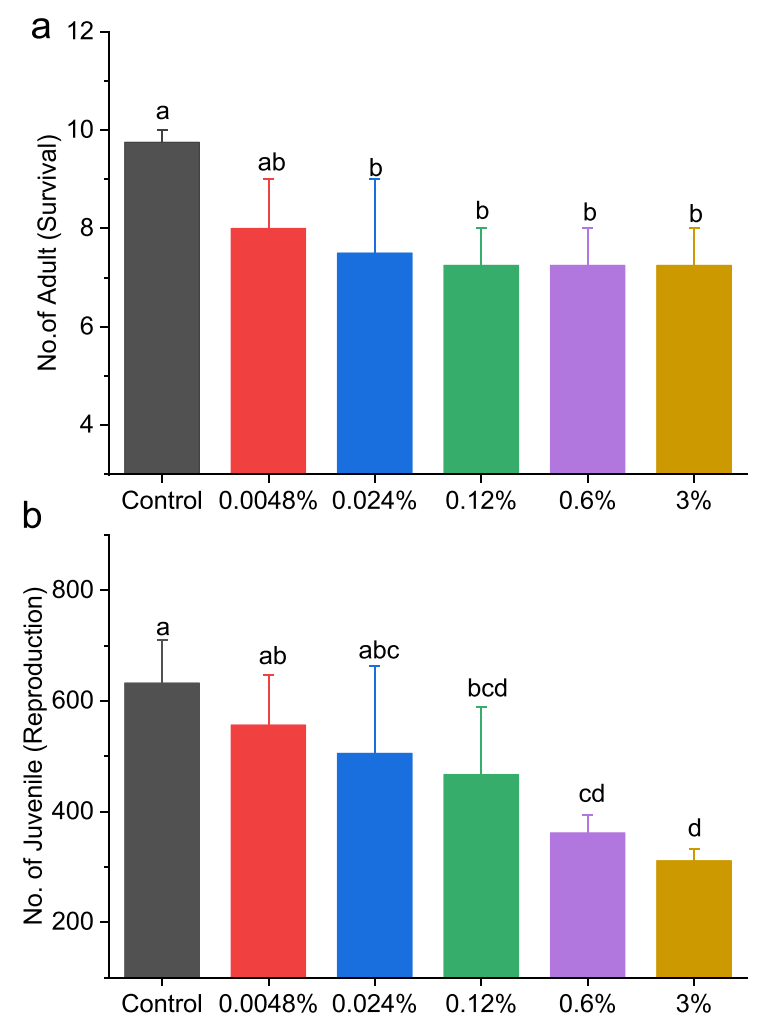

Figure 1. Survival (a) and reproduction (b) of the worms from all TP treatments after 21 days of exposure. Different letters indicate significant differences between different treatments at the 0.05 level, tested by one-way ANOVA.

3543926 high-quality bacterial sequences were obtained from the gut and soil microbiota, respectively, which could be classified into 28334 and 29032 OTUs. For the fungal community, a total of 7375553 and 3079065 high-quality sequences were identified for the gut and soil microbiota, respectively, which could be classified into 11219 and 3422 OTUs. Proteobacteria (33.2\%) and Ascomycota (44.7\%) were the most abundant bacterial and fungal phyla in the gut microbiota, respectively (Figure S6). They were also the most abundant phyla in the soil microbiota, comprising $41.0 \%$ and $41.9 \%$ of the bacterial and fungal OTUs, respectively (Figure S6). Moreover, there were 10 phyla with a relative abundance of above $1 \%$ in both the gut and soil bacterial communities (Figure S6). However, only three fungal phyla, including Ascomycota, Basidiomycota, and Zygomycota, had a relative abundance above $1 \%$ in the worm guts (Figure S6).

There was a significant difference in both bacterial and fungal diversity between the guts and soil ( $t$ test, $P<0.05$, Table 2). The Shannon index revealed a lower bacterial diversity in the worm guts compared to the surrounding soil $(t$ test, $P<0.05$, Table 2). However, an inverse trend was observed for the fungal diversity, by which the fungal diversity was higher in the gut microbiota than the soil microbiota $(t$ test, $P<0.05$, Table 2). A separated principal coordinate analysis (PCoA) plot was used to illustrate dissimilarities between the bacterial communities from the gut and soil samples (Figure 2a). Moreover, the fungal community in the worm guts was also different from the surrounding soil community (Figure $2 \mathrm{~b}$ ). By comparing the relative abundance of the 100 most abundant OTUs, we found that only three bacterial and seven fungal OTUs were at similar levels in both
Table 2. Diversity (Shannon Index) Of the Worms Gut and Soil Microbiota in the Different TP Treatments ${ }^{a}$

\begin{tabular}{|c|c|c|c|c|}
\hline \multirow[b]{2}{*}{ treatment } & \multicolumn{2}{|c|}{ bacteria } & \multicolumn{2}{|c|}{ fungi } \\
\hline & gut & soil & gut & soil \\
\hline control & $8.4 \pm 0.9^{\mathrm{a}}$ & $8.8 \pm 0.2^{\mathrm{a}}$ & $6.2 \pm 0.5^{\mathrm{ab}}$ & $2.8 \pm 0.1^{\mathrm{a}}$ \\
\hline $0.0048 \%$ & $8.0 \pm 0.3^{\mathrm{a}}$ & $8.6 \pm 0.4^{\mathrm{a}}$ & $5.9 \pm 0.5^{\mathrm{a}}$ & $2.9 \pm 0.3^{\mathrm{a}}$ \\
\hline $0.024 \%$ & $7.6 \pm 0.8^{\mathrm{a}}$ & $8.6 \pm 0.1^{a}$ & $6.5 \pm 0.3^{\mathrm{ab}}$ & $3.0 \pm 0.2^{\mathrm{a}}$ \\
\hline $0.12 \%$ & $7.7 \pm 0.2^{\mathrm{a}}$ & $8.9 \pm 0.2^{\mathrm{a}}$ & $6.2 \pm 0.5^{b}$ & $2.8 \pm 0.2^{\mathrm{a}}$ \\
\hline $0.6 \%$ & $7.7 \pm 0.2^{\mathrm{a}}$ & $9.0 \pm 0.2^{\mathrm{a}}$ & $6.2 \pm 0.5^{b}$ & $2.9 \pm 0.4^{\mathrm{a}}$ \\
\hline $3 \%$ & $7.9 \pm 0.2^{\mathrm{a}}$ & $8.9 \pm 0.1^{\mathrm{a}}$ & $6.2 \pm 0.5^{b}$ & $2.8 \pm 0.2^{\mathrm{a}}$ \\
\hline
\end{tabular}

${ }^{a}$ Different letters indicate significant differences between different treatments at the 0.05 level, testing by one-way ANOVA.

the gut and soil microbiota $(t$ test, $P>0.05$, Figures $S 7$ and S8).

No significant difference in the bacterial alpha-diversity was observed in the guts of TP exposed worms compared with the control (ANOVA, $P>0.05$, Table 2). In addition, TP exposure affected neither the bacterial or fungal alpha-diversity of the soil (ANOVA, $P>0.05$, Table 2). PCoA based on BrayCurtis metrics revealed that TP exposure shifted both the bacterial and fungal communities of the worm guts, compared to the control (Figure 2). These shifts were also confirmed by the Adonis and Anosim tests according to Bray-Curtis dissimilarity metrics $(P<0.001$, Figure 2$)$. The microbial community shifts, however, appeared to be dose-dependent, as the shifts were more significant in the high-dose TP treatments than the low-dose treatments (Figure 2; Table S2). Similarly, TP exposure also changed the soil bacterial and fungal communities $(P<0.001$, Figure 2$)$. However, the gut microbiota was more sensitive to TP exposure than the soil microbiota (Figure 2, Table S2). For example, the gut bacterial community was significantly shifted at the $0.0048 \%$ TP dose, while the soil bacterial community was only affected by TP doses over $0.024 \%$ (Table S2).

A taxon-based analysis confirmed that exposure to TPs shifted the gut microbiota of the worms (Figures 3, S7, and S8). To investigate the effects of TPs on the gut microbiota, the 10 most abundant genera were analyzed, revealing that TP exposure significantly changed the relative abundance of eight bacterial and six fungal genera, respectively $(P<0.05$, Figure $3)$. The guts of the worms exposed to TPs had a lower abundance of the bacterial genera Acinetobacter and Cupriavidus compared with the control worms $(P<0.05$, Figure 3a). However, TPs selectively enhanced the relative abundance of six other bacterial genera, such as Alicyclobacillus and Flavobacterium, in a dose-dependent manner (Figure 3a, Table S3). For the fungi, TP exposure caused a decrease in the abundance of Mucor and Penicillium, from $4.7 \%$ and $13.0 \%$ to $0.6 \%$ and $1.8 \%$, respectively (Figure $3 \mathrm{~b}$ ). Besides, the relative abundance of the genus Scolecobasidium increased significantly by 4.7-, 7.7-, 8.5-, 10.5-, and 9.5-fold in the five TP treatments, respectively (Figure $3 \mathrm{~b}$ ). Moreover, pronounced shifts in both the bacterial and fungal OTU profiles of the worm guts exposed to TPs were found (Figures S7 and S8).

According to the ordinary least-squares regression analyses, the gut bacterial community structure correlated significantly with the survival $\left(R^{2}=0.55, P<0.001\right)$ and reproduction $\left(R^{2}\right.$ $=0.43, P<0.001$ ) rate of worms (Figure $4 \mathrm{a}, \mathrm{c}$ ). However, the gut fungal community structure only correlated significantly 

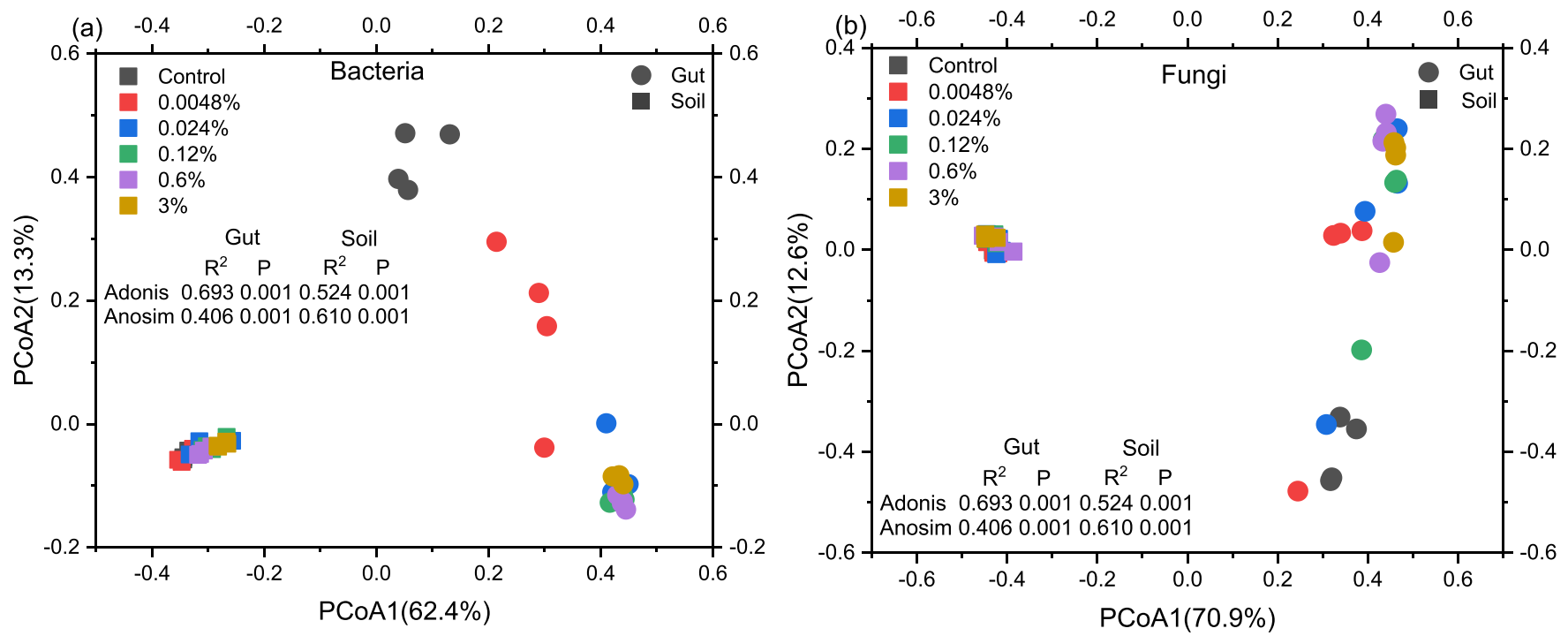

Figure 2. Distribution pattern of the bacterial communities (a) and fungal communities (b) in gut and soil microbiota, revealed by the principal coordinates analysis according to the relative abundance of each OTU based on the Bray-Curtis distance matrix. Differences in the microbial communities of the different treatments were evaluated by the Adonis and Anosim tests at the 0.05 level. The gut and soil microbiota were tested separately.

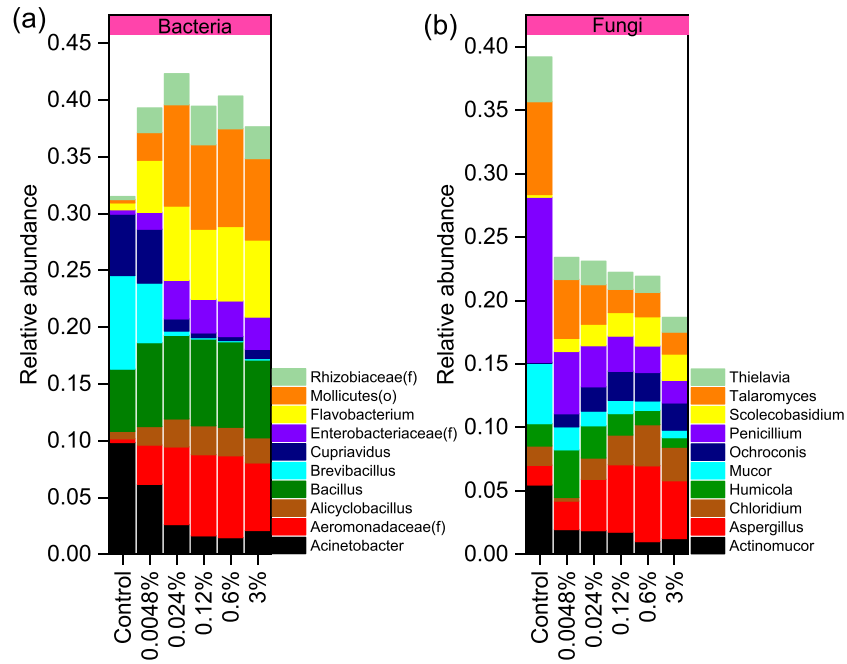

Figure 3. Relative abundance of the most abundant ten genera of the bacterial community (a) and fungal community (b) of the worm guts from all TP treatments after 21 days of exposure. If annotation of the genus or family level was not possible, then the family or order was denoted by (f) or (o).

with the reproduction rate of worms $\left(R^{2}=0.41, P<0.001\right.$, Figure 4d).

Co-variation between Bacterial and Fungal Communities in Worm Guts. The Mantel test revealed a significant correlation between the bacterial and fungal communities in the worm guts $(R=0.64, P<0.001)$, which was further confirmed by the Procrustes analysis (Figure 5a, $\left.M^{2}=0.50, P<0.001\right)$. The complex associations between cross-kingdom gut microbial communities were, in addition, confirmed by a co-occurrence analysis (Figure $5 \mathrm{~b}$ and Table S5).

\section{DISCUSSION}

TP Amendment Increased Heavy Metal and PAH concentrations in Soil. In the present study, we found high concentrations of $\mathrm{Zn}$, pyrene, benz[a]anthracene, chrysene, and benzo[b]fluoranthene in TPs used in this study (Table 1). The detected concentrations of heavy metals and PAHs in the TPs were at the similar levels as reported previously. ${ }^{14,38}$ For example, Aatmeeyata et al. (2010) summarized the total PAH concentrations in TPs from different studies and found that they ranged between 13.5 and $112 \mathrm{mg} \mathrm{kg}^{-1}$. $^{38}$ Multiple factors can affect PAH contents in TPs, such as tire mileage, which can increase the concentrations due to thermal degradation of the tire. ${ }^{38,39}$

Although various metals were detected in TPs, $\mathrm{Zn}$, which was added to tires during the vulcanization process, ${ }^{14}$ was the only heavy metal that increased in the soil-TP mixtures (Table S1, Figure S3), in consistence with previous findings. ${ }^{28}$ This implies that the content of other heavy metals in the TPs was not sufficient to cause measurable changes and further confirms that TPs are a potential source of $\mathrm{Zn}$ pollution in the environment. $^{40,41}$ The $\mathrm{Zn}$ could be released from the TPs into environments and induce adverse effects on organisms. ${ }^{14,42}$ In addition, our results revealed that $\mathrm{TP}$ amendment increased the concentration of a specific type of PAH in the soil-TP mixtures (Table S1, Figure S4), which is in agreement with previous studies, reporting increased accessibility of PAHs in particulate matter from road-impacted environments. ${ }^{43,44}$ TPs, are therefore likely a potential source of both $\mathrm{Zn}$ and PAHs in the environment, and might affect the performance of environmental biota and even threaten human health. For example, TP leachate exposure caused severe development malformation of amniote vertebrate. ${ }^{45}$

TP Amendment Decreased the Survival and Reproduction Rate of Worms. TP exposure had a dose-dependent effect on the reproduction of worms (Figures 1 and S5). Compared with the reproduction of worms, the decreased trend of survival rate to TPs exposure was inconspicuous (Figure 1). This was consistent with the general observations in the ecotoxicological studies that the change of reproduction was more sensitive to contaminant than that of survival rate. ${ }^{22}$ To our knowledge, this is the first study to report that TP exposure can harm soil fauna. Numerous studies have revealed 

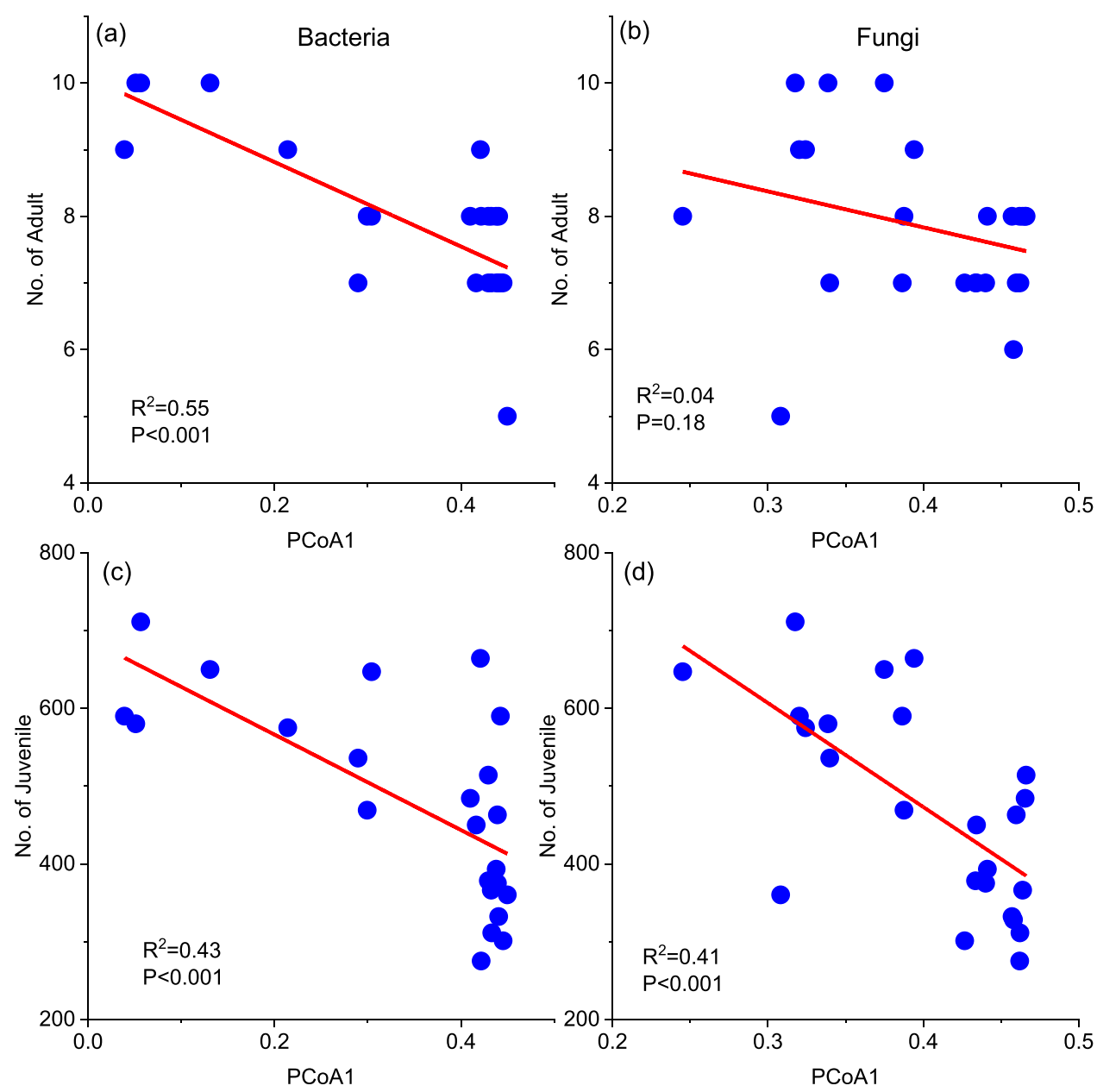

Figure 4. Regression between the gut microbiota (bacterial and fungal community structure) and survival (a, b) and reproduction (c, d) rate of worms.

acute and chronic toxicity of TPs on aquatic organisms including fish, copepods, decapods, bacteria, and algae. ${ }^{9,46-48}$ The toxicity of TPs is probably similar for soil fauna as for aquatic organisms, and are likely caused by leaching of $\mathrm{Zn}$ and organic compounds. ${ }^{11,12,14,42}$ Although we considered $\mathrm{Zn}$ and PAHs in this study, other potential toxicants should not be ruled out, for example, a variety of chlorinated paraffins have been detected in TPs ${ }^{49}$ and future studies should be conducted to investigate their adverse effects on soil fauna. Moreover, our previous study, as well as others, suggested that exposure to MPs might lead to blockage of the digestive tract or irritation of the mucosa of biota. ${ }^{23,50,51}$ Since TPs are a special class of MPs, they might also be lethal for soil fauna through physical damage. In addition, MPs have been revealed to affect the hatching of both aquatic and terrestrial animal eggs, which might be partly explained by a reduction in reproduction. ${ }^{52}$ The combination of chemical and physical factors of TPs led to the adverse effects on soil worms, and the leachates might contribute more, as a variety of toxicants could be released from TPs.

TP Amendment Disturbed the Microbiota of the Worm Guts and Soil. High throughput sequencing revealed that TP exposure changed both the bacterial and fungal communities of the soil microbiota (Figure 2). Smolders and Degryse (2002) found that amendment with TPs increased the nitrification potential of soil, possibly due to increases in soil $\mathrm{pH}^{41}$ However, $\mathrm{Zn}$ leachates from TPs might also affect the soil microbiota since $\mathrm{Zn}$ is an important driver of the soil microbial community structure. In this study, TP-induced changes in basic properties of the soil, and increased soil $\mathrm{Zn}$ concentrations could explain shifts in the soil microbiota. Moreover, a TP dose-dependent response of the gut bacterial and fungal communities was observed (Figure 2, Table S2). Exposure to organic fertilizers or soil contamination has been shown to disturb the gut bacterial community of soil collembolans and earthworms. ${ }^{25,53}$ In addition, micro- and nanoplastics can induce shifts in the gut microbiota of soil fauna. ${ }^{22,23}$ Moreover, leaching of plastic additives as well as physical damage induced by MPs, such as scratching of the gut mucosa, are considered important factors affecting the gut microbiota of organisms. ${ }^{54,55}$ Hence, the combined physical and chemical effects of TPs might cause the observed dysbiosis in the gut microbiota of the worms. This partly explained the non-gradient responses of gut microbiota to TPs exposure (Figure 3). A recent study has revealed that MPs can perturb the gut microbiota of E. crypticus at high doses $(>0.1 \%)$; $^{22}$ however, in our study, TP exposure significantly changed the gut microbiota of the worms at a lower dose of $0.0048 \%$ (Figure 2, Table S2). The toxicity of TP leachates thereby seems more problematic than MP leachates, possibly due to higher concentrations of $\mathrm{Zn}, \mathrm{PAHs}$, and other toxicants, which can affect the gut microbiota of soil fauna. ${ }^{56,57}$

The present study revealed that the gut microbiota was more sensitive to TP exposure than the soil microbiota (Figure 2, 


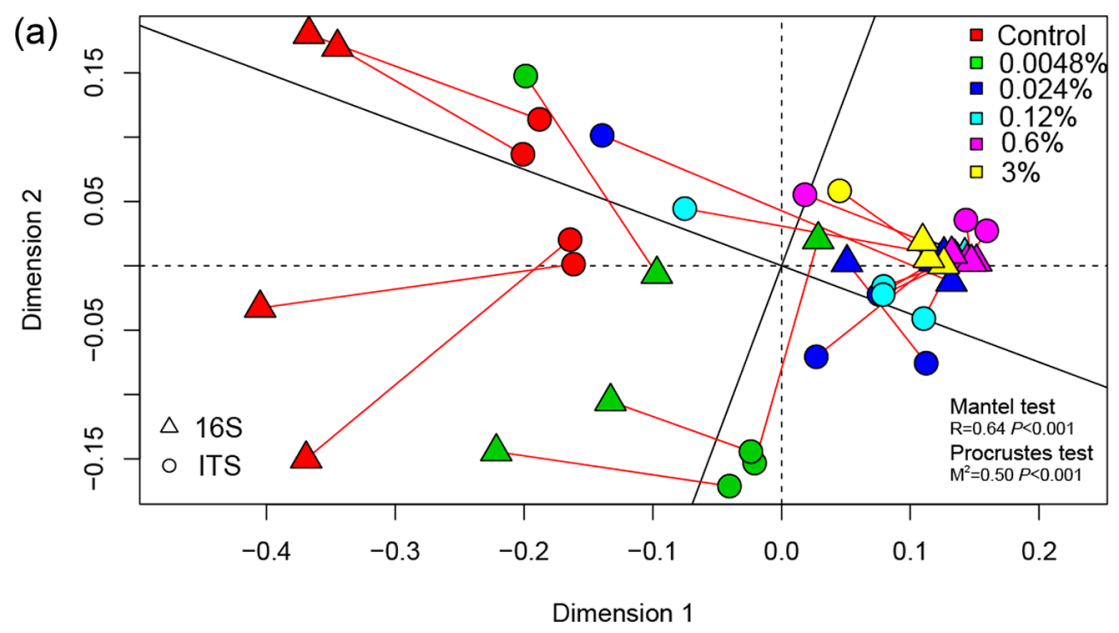

(b)

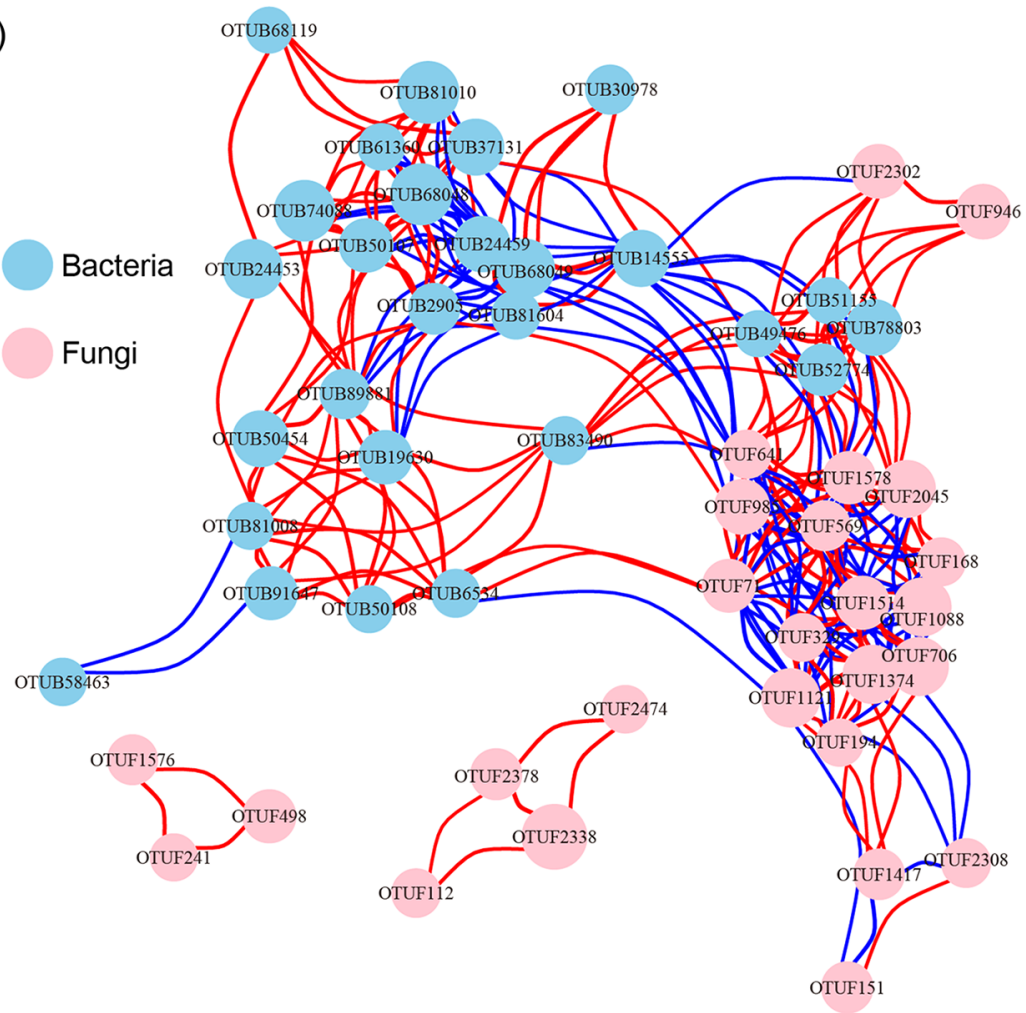

Figure 5. Co-variation of the bacterial and fungal communities in the worm guts exposed to TPs, revealed by Procrustes analysis (a) and cooccurrence network (b). The relative abundance of each OTU and the most abundant 30 OTUs was selected in the Procrustes analysis and cooccurrence network, respectively.

Table S2), which might be explained by three main reasons. First, the gut microbiota is closely connected with the condition of the host, and TP exposure might affect the host's feeding behavior and nutrient assimilation, which could indirectly affect the gut microbiota. ${ }^{23}$ Second, the gut may accelerate the release of contaminates from TPs. ${ }^{7}$ For instance, the gut fluids of lugworms can affect the bioavailability of PAHs from TPs, which usually are strongly bound and not easily leached. ${ }^{58,59}$ Additionally, the toxicants released from TPs, especially the PAHs, could be bioaccumulated in the body of worms and that may increase the toxicity to organisms. ${ }^{60}$ All mentioned above might increase the sensibility of the gut microbiota to soil pollutants, which highlights the need for including the gut microbiota of soil fauna when evaluating the toxicity of soil pollutants.
The taxon-based analysis revealed that TP exposure changed the relative abundance of the most abundant bacterial and fungal taxa in the worm guts (Figure 3, Table S3). For example, two unassigned genera from the bacterial families Enterobacteriaceae and Aeromonadaceae were significantly increased by the TP exposure (Figure 3). These bacterial families have previously been associated with intestinal inflammatory disorders, further confirming the adverse effects of TPs on soil fauna. ${ }^{61-63}$ Moreover, TP exposure led to an increase in genera containing several pathogenic species, including the bacterial genera Flavobacterium and Aeromonadaceae and the fungal genera Scolecobasidium and Ochroconis (Figure 3, Table S3)..$^{51,64,65}$ Soil fauna is considered vectors in soil, as they can transport and disperse various microorganisms between environments, including pathogens. Therefore, if TP 
exposure increases the abundance of pathogens in worms, then it would increase the risk for transfer of pathogens in the soil food web, which might be an emerging threat to soil ecosystems. Changes in the gut microbiota may further influence the functions that soil fauna conducts in soil ecosystems. For instance, the reduction in the fungal genera Talaromyces and Penicillium can reduce organic matter decomposition since these fungi are involved in litter decomposition in soil ecosystems (Figure 3, Table S3). ${ }^{66,67}$ Similarly, the genus Bacillus, which is involved in the decomposition of organic matter and nutrient cycling, significantly declined after exposure to TPs (Figure 3, Table S3). ${ }^{68,69}$ All the above suggest that TP exposure constitute a risk affecting the eco-function of soil fauna.

Our results, in addition, showed that there were significant regressions between the gut microbiota and the worms' survival and reproduction rates (Figure 4). Previous studies have demonstrated that the gut microbiota of soil fauna can influence the assimilation and dissimilation of carbon and nitrogen, thereby affecting nutrient turnover. ${ }^{70}$ A decrease in the survival and reproduction rates of the worms caused by the dysbiosis in the gut microbiota due to $\mathrm{TP}$ exposure further confirmed the important role of the gut microbiota in soil fauna and highlighted the need for investigating the gut microbiota of target organisms during ecotoxicological experiments. This may further explain the toxicity of tire tread particles to soil worms.

TP Amendment Induced a Co-variation between Bacterial and Fungal Communities in Worm Guts. A considerable covariation between bacterial and fungal communities, as well as extensive cross-kingdom associations, were demonstrated in the worm guts exposed to TPs (Figure 5). Similar variations in bacterial and fungal communities have been observed in the microbiome of insects and plants exposed to environmental changes. ${ }^{71,72}$ For example, bacterial and fungal communities in ash leaves were strongly associated with one another, and variations in their composition correlated with the degree of pathogenic infection. ${ }^{73}$ Generally, bacterial and fungal communities are competing for resources; however, the strong connections between bacterial and fungal taxa in the worm guts in this study indicated a link between competitions for niche occupancy. The strong connections between these two kingdoms in guts may influence the host to improve resistance to environment stress, which warrants considerable attention.

In summary, the present study showed that TPs contained high concentrations of $\mathrm{Zn}$ and PAHs, which might lead to $\mathrm{Zn}$ and $\mathrm{PAH}$ contamination in the environment. TP exposure caused a dose-dependent effect on the survival and reproduction of worms. Furthermore, the bacterial and fungal communities of the worm guts and soil were affected by the TP exposure. It is revealed that the gut microbiota appeared to be more sensitive to TP exposure than the soil microbiota, and thus likely played an important role in the survival and reproduction of the soil fauna. TP exposure also increased the occurrence of microbial genera associated with opportunistic pathogenesis and affected microbes involved in the ecofunctions of the worms. Moreover, there was a significant association between TP dose and the gut bacterial and fungal community compositions. This suggests that a covariation between the bacterial and fungal communities occurs in the soil fauna guts during environmental stress. These findings provide some insights into the adverse effects of TPs on soil biota and highlight the emerging threat of TPs to soil ecosystems.

\section{ASSOCIATED CONTENT}

\section{Supporting Information}

The Supporting Information is available free of charge at https://pubs.acs.org/doi/10.1021/acs.est.0c00917.

Table S1, Concentration of heavy metals and PAHs in soil-TP mixtures with different TP treatments; Table S2, differences in worm gut and soil bacterial and fungal communities between different TP treatments; Table S3, differences in the top 10 bacterial and fungal genera between the worms guts of different TP treatments; Table S4, detailed information for the OTUs in cooccurrence network; Figure S1, photograph about TPs used in the present study; Figure S2, particle size distribution of the TPs in relation to volume of the particles; Figure S3, linear correlation between the TP concentrations and the measured Zinc ( $\mathrm{Zn}$ ) concentrations in the soil-TP mixtures; Figure S4, linear correlation between the TP concentrations and the PAH concentrations in the soil-TP mixture; Figure S5, logarithmic correlation between the $\mathrm{TP}$ concentrations and the number of juvenile worms in the soil-TP mixtures; Figure S6, bar plot showing the relative abundance of different bacterial phyla and fungal phyla in the microbiota of the worm guts and soil from the different TP treatments; Figure S7, heat map showing the relative abundance of the top 100 bacterial OTUs of the worm gut and-soil microbiota from the different TP treatments; and Figure S8, heat map showing the relative abundance of the top 100 fungal OTUs of the worm gut and-soil microbiota from the different TP treatments (PDF)

\section{AUTHOR INFORMATION}

\section{Corresponding Author}

Yong-Guan Zhu - State Key Laboratory of Urban and Regional Ecology, Research Centre for Eco-Environmental Sciences, Chinese Academy of Sciences, Beijing 100085, P. R. China; Key Laboratory of Urban Environment and Health, Institute of Urban Environment, Chinese Academy of Sciences, Xiamen 361021, P. R. China; 이이이.org/0000-0003-3861-8482; Phone: +86-10-62936940; Email: ygzhu@rcees.ac.cn; Fax: +86-10-62936940

\section{Authors}

Jing Ding - School of Environmental and Material Engineering, Yantai University, Yantai 264005, P. R. China

Dong Zhu - State Key Laboratory of Urban and Regional Ecology, Research Centre for Eco-Environmental Sciences, Chinese Academy of Sciences, Beijing 100085, P. R. China

Hong-Tao Wang - Key Laboratory of Urban Environment and Health, Institute of Urban Environment, Chinese Academy of Sciences, Xiamen 361021, P. R. China

Simon Bo Lassen - Key Laboratory of Urban Environment and Health, Institute of Urban Environment, Chinese Academy of Sciences, Xiamen 361021, P. R. China; Department of Plant and Environmental Sciences, Faculty of Science, University of Copenhagen, 1871 Frederiksberg, Denmark; Sino-Danish Center for Education and Research (SDC), University of Chinese Academy of Sciences, Beijing 100190, P. R. China 
Qing-Lin Chen - Faculty of Veterinary and Agricultural Sciences, The University of Melbourne, Parkville, Victoria 3010, Australia; orcid.org/0000-0002-5648-277X

Gang Li - Key Laboratory of Urban Environment and Health, Institute of Urban Environment, Chinese Academy of Sciences, Xiamen 361021, P. R. China

Min Lv - Key Laboratory of Coastal Environmental Processes and Ecological Remediation, Yantai Institute of Coastal Zone Research, Chinese Academy of Sciences, Yantai 264003, P. R. China

Complete contact information is available at: https://pubs.acs.org/10.1021/acs.est.0c00917

\section{Author Contributions \\ OJ.D. and D.Z. contributed equally to this paper. \\ Notes}

The authors declare no competing financial interest.

\section{ACKNOWLEDGMENTS}

This study was funded by the National Science Foundation of China (41807032 and 41601525). We thank Mr. Zu Fei Xiao and Mrs. Le Hui Song for their contributions to the heavy metals and PAHs analysis.

\section{REFERENCES}

(1) Thompson, R. C.; Olsen, Y.; Mitchell, R. P.; Davis, A.; Rowland, S. J.; John, A. W. G.; McGonigle, D.; Russell, A. E. Lost at sea: Where is all the plastic? Science 2004, 304 (5672), 838-838.

(2) Chae, Y.; An, Y. J. Effects of micro- and nanoplastics on aquatic ecosystems: Current research trends and perspectives. Mar. Pollut. Bull. 2017, 124 (2), 624-632.

(3) Rillig, M. C. Microplastic in terrestrial ecosystems and the soil? Environ. Sci. Technol. 2012, 46 (12), 6453-6454.

(4) Wright, S. L.; Kelly, F. J. Plastic and human health: A micro issue? Environ. Sci. Technol. 2017, 51 (12), 6634-6647.

(5) Kole, P. J.; Lohr, A. J.; Van Belleghem, F. G. A. J.; Ragas, A. M. J. Wear and tear of tyres: A stealthy source of microplastics in the environment. Int. J. Environ. Res. Public Health 2017, 14 (10), 1265.

(6) Wagner, S.; Hueffer, T.; Kloeckner, P.; Wehrhahn, M.; Hofmann, T.; Reemtsma, T. Tire wear particles in the aquatic environment - A review on generation, analysis, occurrence, fate and effects. Water Res. 2018, 139, 83-100.

(7) Wik, A.; Dave, G. Occurrence and effects of tire wear particles in the environment - A critical review and an initial risk assessment. Environ. Pollut. 2009, 157 (1), 1-11.

(8) Skjolding, L. M.; Sorensen, S. N.; Hartmann, N. B.; Hjorth, R.; Hansen, S. F.; Baun, A. Aquatic ecotoxicity testing of nanoparticles the quest to dsclose nanoparticle effects. Angew. Chem., Int. Ed. 2016, 55 (49), 15224-15239.

(9) Marwood, C.; McAtee, B.; Kreider, M.; Ogle, R. S.; Finley, B.; Sweet, L.; Panko, J. Acute aquatic toxicity of tire and road wear particles to alga, daphnid, and fish. Ecotoxicology 2011, 20 (8), 20792089.

(10) Villena, O. C.; Terry, I.; Iwata, K.; Landa, E. R.; LaDeau, S. L.; Leisnham, P. T. Effects of tire leachate on the invasive mosquito Aedes albopictus and the native congener Aedes triseriatus. PeerJ 2017, 5, e3756.

(11) Wik, A.; Nilsson, E.; Kallqvist, T.; Tobiesen, A.; Dave, G. Toxicity assessment of sequential leachates of tire powder using a battery of toxicity tests and toxicity identification evaluations. Chemosphere 2009, 77 (7), 922-927.

(12) Gualtieri, M.; Andrioletti, M.; Vismara, C.; Milani, M.; Camatini, M. Toxicity of tire debris leachates. Environ. Int. 2005, 31 (5), 723-730.

(13) Sheehan, P. J.; Warmerdam, J. M.; Ogle, S.; Humphrey, D. N.; Patenaude, S. M. Evaluating the risk to aquatic ecosystems posed by leachate from tire shred fill in roads using toxicity tests, toxicity identification evaluations, and groundwater modeling. Environ. Toxicol. Chem. 2006, 25 (2), 400-411.

(14) Rhodes, E. P.; Ren, Z.; Mays, D. C. Zinc leaching from tire crumb rubber. Environ. Sci. Technol. 2012, 46 (23), 12856-12863.

(15) Turner, A.; Rice, L. Toxicity of tire wear particle leachate to the marine macroalga, Ulva lactuca. Environ. Pollut. 2010, 158 (12), $3650-3654$.

(16) Sadiktsis, I.; Bergvall, C.; Johansson, C.; Westerholm, R. Automobile tires-A potential source of highly carcinogenic dibenzopyrenes to the environment. Environ. Sci. Technol. 2012, 46 (6), 3326-3334.

(17) Van Duijnhove, N.; Denier van der Gon, H.; Hulskotte, J., Emissieschattingen diffuse Bronnen Emissieregistratie-Bandenslijtage Wegverkeer-Versie Mei. DELTARES en TNO: Delft, The Netherlands 2014.

(18) Halle, L. L.; Palmqvist, A.; Kampmann, K.; Khan, F. R. Ecotoxicology of micronized tire rubber: Past, present and future considerations. Sci. Total Environ. 2020, 706, 135694-135694.

(19) De Deyn, G. B.; Raaijmakers, C. E.; Zoomer, H. R.; Berg, M. P.; de Ruiter, P. C.; Verhoef, H. A.; Bezemer, T. M.; van der Putten, W. $\mathrm{H}$. Soil invertebrate fauna enhances grassland succession and diversity. Nature 2003, 422 (6933), 711-713.

(20) Gonzalez, G.; Seastedt, T. R. Soil fauna and plant litter decomposition in tropical and subalpine forests. Ecology 2001, 82 (4), 955-964.

(21) Kuiper, I.; de Deyn, G. B.; Thakur, M. P.; van Groenigen, J. W. Soil invertebrate fauna affect $\mathrm{N}_{2} \mathrm{O}$ emissions from soil. Glob. Chang. Biol. 2013, 19 (9), 2814-2825.

(22) Zhu, B. K.; Fang, Y. M.; Zhu, D.; Christie, P.; Ke, X.; Zhu, Y. G. Exposure to nanoplastics disturbs the gut microbiome in the soil oligochaete Enchytraeus crypticus. Environ. Pollut. 2018, 239, 408-415.

(23) Zhu, D.; Chen, Q. L.; An, X. L.; Yang, X. R.; Christie, P.; Ke, X.; Wu, L. H.; Zhu, Y. G. Exposure of soil collembolans to microplastics perturbs their gut microbiota and alters their isotopic composition. Soil Biol. Biochem. 2018, 116, 302-310.

(24) Claus, S. P.; Guillou, H.; Ellero-Simatos, S. The gut microbiota: a major player in the toxicity of environmental pollutants? $N p j$ Biofilms Microbi. 2016, 2 (1), 1-11.

(25) Zhu, D.; An, X. L.; Chen, Q. L.; Yang, X. R.; Christie, P.; Ke, X.; Wu, L. H.; Zhu, Y. G. Antibiotics disturb the microbiome and increase the incidence of resistance genes in the gut of a common soil Ccollembolan. Environ. Sci. Technol. 2018, 52 (5), 3081-3090.

(26) Anslan, S.; Bahram, M.; Tedersoo, L. Temporal changes in fungal communities associated with guts and appendages of Collembola as based on culturing and high-throughput sequencing. Soil Biol. Biochem. 2016, 96, 152-159.

(27) Anslan, S.; Bahram, M.; Tedersoo, L. Seasonal and annual variation in fungal communities associated with epigeic springtails (Collembola spp.) in boreal forests. Soil Biol. Biochem. 2018, 116, 245-252.

(28) Redondo-Hasselerharm, P. E.; de Ruijter, V. N.; Mintenig, S. M.; Verschoor, A.; Koelmans, A. A. Ingestion and chronic effects of car tire tread particles on freshwater benthic macroinvertebrates. Environ. Sci. Technol. 2018, 52 (23), 13986-13994.

(29) OECD. Test No. 220: Enchytraeid reproduction test, OECD guidelines for the testing of chemicals, section 2. Organisation for Economic Co-operation and Development: Paris, France,2004. DOI: $10.1787 / 9789264070301-$ en.

(30) Berg, M.; Stenuit, B.; Ho, J.; Wang, A.; Parke, C.; Knight, M.; Alvarez-Cohen, L.; Shapira, M. Assembly of the Caenorhabditis elegans gut microbiota from diverse soil microbial environments. ISME J. 2016, 10 (8), 1998-2009.

(31) Ding, J.; Zhu, D.; Li, H.; Ding, K.; Chen, Q. L.; Lassen, S. B.; $\mathrm{Ke}, \mathrm{X}$.; O'Connor, P.; Zhu, Y. G. The gut microbiota of soil organisms show species-specific responses to liming. Sci. Total Environ. 2019, $659,715-723$.

(32) Ihrmark, K.; Bodeker, I. T. M.; Cruz-Martinez, K.; Friberg, H.; Kubartova, A.; Schenck, J.; Strid, Y.; Stenlid, J.; Brandstrom-Durling, 
M.; Clemmensen, K. E.; Lindahl, B. D. New primers to amplify the fungal ITS2 region - evaluation by 454-sequencing of artificial and natural communities. FEMS Microbiol. Ecol. 2012, 82 (3), 666-677.

(33) Caporaso, J. G.; Kuczynski, J.; Stombaugh, J.; Bittinger, K.; Bushman, F. D.; Costello, E. K.; Fierer, N.; Pena, A. G.; Goodrich, J. K.; Gordon, J. I.; et al. QIIME allows analysis of high-throughput community sequencing data. Nat. Methods 2010, 7 (5), 335-336.

(34) Chen, Q. L.; Ding, J.; Zhu, D.; Hu, H. W.; Delgado-Baquerizo, M.; Ma, Y. B.; He, J. Z.; Zhu, Y. G. Rare microbial taxa as the major drivers of ecosystems multifunctionality in long-term fertilized soils. Soil Biol. Biochem. 2020, 141, 107686.

(35) Edgar, R. C. Search and clustering orders of magnitude faster than BLAST. Bioinformatics 2010, 26 (19), 2460-2461.

(36) Cole, J. R.; Wang, Q.; Cardenas, E.; Fish, J.; Chai, B.; Farris, R. J.; Kulam-Syed-Mohideen, A. S.; McGarrell, D. M.; Marsh, T.; Garrity, G. M.; Tiedje, J. M. The ribosomal database project: Improved alignments and new tools for rRNA analysis. Nucleic Acids Res. 2009, 37, D141-D145.

(37) Nilsson, R. H.; Larsson, K.-H.; Taylor, A. F. S.; BengtssonPalme, J.; Jeppesen, T. S.; Schigel, D.; Kennedy, P.; Picard, K.; Gloeckner, F. O.; Tedersoo, L.; Saar, I.; Koljalg, U.; Abarenkov, K. The UNITE database for molecular identification of fungi: handling dark taxa and parallel taxonomic classifications. Nucleic Acids Res. 2019, 47 (D1), D259-D264.

(38) Aatmeeyata; Sharma, M. Polycyclic aromatic hydrocarbons, elemental and organic carbon emissions from tire-wear. Sci. Total Environ. 2010, 408 (20), 4563-4568.

(39) Kwon, E. E.; Castaldi, M. J. Mechanistic Understanding of polycyclic aromatic hydrocarbons (PAHs) from the thermal degradation of tires under various oxygen concentration atmospheres. Environ. Sci. Technol. 2012, 46 (23), 12921-12926.

(40) Councell, T. B.; Duckenfield, K. U.; Landa, E. R.; Callender, E. Tire-wear particles as a source of zinc to the environment. Environ. Sci. Technol. 2004, 38 (15), 4206-4214.

(41) Smolders, E.; Degryse, F. Fate and effect of Zinc from tire debris in soil. Environ. Sci. Technol. 2002, 36 (17), 3706-3710.

(42) Kolomijeca, A.; Parrott, J. L.; Khan, H.; Shires, K.; Clarence, S.; Sullivan, C.; Chibwe, L.; Sinton, D.; Rochman, C. M. Increased temperature and turbulence alter the effects of leachates from tire particles on fathead minnow (Pimephales promelas). Environ. Sci. Technol. 2020, 54 (3), 1750-1759.

(43) Allan, I. J.; O’Connell, S. G.; Meland, S.; Baek, K.; Grung, M.; Anderson, K. A.; Ranneklev, S. B. PAH accessibility in particulate matter from road-impacted environments. Environ. Sci. Technol. 2016, 50 (15), 7964-7972.

(44) Anh, H. Q.; Minh, T. B.; Tran, T. M.; Takahashi, S. Road dust contamination by polycyclic aromatic hydrocarbons and their methylated derivatives in northern Vietnam: Concentrations, profiles, emission sources, and risk assessment. Environ. Pollut. 2019, 254, 113073.

(45) Xu, E. G.; Lin, N.; Cheong, R. S.; Ridsdale, C.; Tahara, R.; Du, T. Y.; Das, D.; Zhu, J.; Silva, L. P.; Azimzada, A.; Larsson, H. C. E.; Tufenkji, N. Artificial turf infill associated with systematic toxicity in an amniote vertebrate. Proc. Natl. Acad. Sci. U. S. A. 2019, 116 (50), 25156-25161.

(46) Khan, F. R.; Halle, L. L.; Palmqvist, A. Acute and long-term toxicity of micronized car tire wear particles to Hyalella azteca. Aquat. Toxicol. 2019, 213 (4), 105216.

(47) Panko, J. M.; Kreider, M. L.; McAtee, B. L.; Marwood, C. Chronic toxicity of tire and road wear particles to water- and sediment-dwelling organisms. Ecotoxicology 2013, 22 (1), 13-21.

(48) Wik, A.; Dave, G. Acute toxicity of leachates of tire wear material to Daphnia magna - Variability and toxic components. Chemosphere 2006, 64 (10), 1777-1784.

(49) Brandsma, S. H.; Brits, M.; Groenewoud, Q. R.; van Velzen, M. J. M.; Leonards, P. E. G.; de Boer, J. Chlorinated Paraffins in Car Tires Recycled to Rubber Granulates and Playground Tiles. Environ. Sci. Technol. 2019, 53 (13), 7595-7603.
(50) Huerta Lwanga, E.; Gertsen, H.; Gooren, H.; Peters, P.; Salanki, T.; van der Ploeg, M.; Besseling, E.; Koelmans, A. A.; Geissen, V. Microplastics in the terrestrial ecosystem: Implications for lumbricus terrestris (Oligochaeta, Lumbricidae). Environ. Sci. Technol. 2016, 50 (5), 2685-2691.

(51) Rehse, S.; Kloas, W.; Zarfl, C. Short-term exposure with high concentrations of pristine microplastic particles leads to immobilisation of Daphnia magna. Chemosphere 2016, 153, 91-99.

(52) Razak, S. A.; Griffin, M. J.; Mischke, C. C.; Bosworth, B. G.; Waldbieser, G. C.; Wise, D. J.; Marsh, T. L.; Scribner, K. T. Biotic and abiotic factors influencing channel catfish egg and gut microbiome dynamics during early life stages. Aquaculture 2019, 498, 556-567.

(53) Ding, J.; Zhu, D.; Hong, B.; Wang, H. T.; Li, G.; Ma, Y. B.; Tang, Y. T.; Chen, Q. L. Long-term application of organic fertilization causes the accumulation of antibiotic resistome in earthworm gut microbiota. Environ. Int. 2019, 124, 145-152.

(54) Chae, Y.; An, Y. J. Current research trends on plastic pollution and ecological impacts on the soil ecosystem: A review. Environ. Pollut. 2018, 240, 387-395.

(55) de Souza Machado, A. A.; Kloas, W.; Zarfl, C.; Hempel, S.; Rillig, M. C. Microplastics as an emerging threat to terrestrial ecosystems. Glob. Chang. Biol. 2018, 24 (4), 1405-1416.

(56) Ding, J.; An, X. L.; Lassen, S. B.; Wang, H. T.; Zhu, D.; Ke, X. Heavy metal-induced co-selection of antibiotic resistance genes in the gut microbiota of collembolans. Sci. Total Environ. 2019, 683, 210215.

(57) Stefaniuk, M.; Oleszczuk, P. Addition of biochar to sewage sludge decreases freely dissolved PAHs content and toxicity of sewage sludge-amended soil. Environ. Pollut. 2016, 218, 242-251.

(58) Kreider, M. L.; Panko, J. M.; McAtee, B. L.; Sweet, L. I.; Finley, B. L. Physical and chemical characterization of tire-related particles: Comparison of particles generated using different methodologies. Sci. Total Environ. 2010, 408 (3), 652-659.

(59) Voparil, I. M.; Burgess, R. M.; Mayer, L. M.; Tien, R.; Cantwell, M. G.; Ryba, S. A. Digestive bioavailability to a deposit feeder (Arenicola marina) of polycyclic aromatic hydrocarbons associated with anthropogenic particles. Environ. Toxicol. Chem. 2004, 23 (11), $2618-2626$

(60) Umeh, A. C.; Panneerselvan, L.; Duan, L.; Naidu, R.; Semple, $\mathrm{K}$. T. Bioaccumulation of benzo a pyrene nonextractable residues in soil by Eisenia fetida and associated background-level sublethal genotoxicity (DNA single-strand breaks). Sci. Total Environ. 2019, 691, 605-610.

(61) Rigottier-Gois, L. Dysbiosis in inflammatory bowel diseases: the oxygen hypothesis. ISME J. 2013, 7 (7), 1256-1261.

(62) Takahashi, E.; Ozaki, H.; Fujii, Y.; Kobayashi, H.; Yamanaka, H.; Arimoto, S.; Negishi, T.; Okamoto, K. Properties of hemolysin and protease produced by Aeromonas trota. PLoS One 2014, 9 (3), e91149.

(63) Winter, S. E.; Winter, M. G.; Xavier, M. N.; Thiennimitr, P.; Poon, V.; Keestra, A. M.; Laughlin, R. C.; Gomez, G.; Wu, J.; Lawhon, S. D.; Popova, I. E.; Parikh, S. J.; Adams, L. G.; Tsolis, R. M.; Stewart, V. J.; Baeumler, A. J. Host derived nitrate boosts growth of E. coli in the inflamed gut. Science 2013, 339 (6120), 708-711.

(64) Samerpitak, K.; Choi, H. J.; van den Ende, A.; Machouart, M.; Gueidan, C.; de Hoog, G. S. A new fungal order for pathogens in Ochroconis and Scolecobasidium. Mycoses 2012, 55, 256-256.

(65) Wang, C.; Sun, G. X.; Li, S. S.; Li, X.; Liu, Y. Intestinal microbiota of healthy and unhealthy Atlantic salmon Salmo salar L. in a recirculating aquaculture system. J. Oceanol. Limnol. 2018, 36 (2), 414-426.

(66) Mahanta, K.; Jha, D. K.; Rajkhowa, D. J.; Kumar, M. Isolation and evaluation of native cellulose degrading microorganisms for efficient bioconversion of weed biomass and rice straw. J. Environ. Biol. 2014, 35 (4), 721-725.

(67) Yilmaz, N.; Lopez-Quintero, C. A.; Vasco-Palacios, A.; Frisvad, J. C.; Theelen, B.; Boekhout, T.; Samson, R. A.; Houbraken, J. Four novel Talaromyces species isolated from leaf litter from Colombian Amazon rain forests. Mycol. Prog. 2016, 15 (10-11), 1041-1056. 
(68) Mandic-Mulec, I.; Stefanic, P.; van Elsas, J. D.Ecology of Bacillaceae. Microbiol. Spectrum 2015, 3 (2) DOI: 10.1128/microbiolspec.TBS-0017-2013.

(69) Mongkolthanaruk, W. Classification of bacillus beneficial substances related to plants, humans and animals. J. Microbiol. Biotechnol. 2012, 22 (12), 1597-1604.

(70) Xiang, Q.; Zhu, D.; Chen, Q. L.; O’Connor, P.; Yang, X. R.; Qiao, M.; Zhu, Y. G. Adsorbed sulfamethoxazole exacerbates the effects of polystyrene (similar to $2 \mathrm{mu} \mathrm{m}$ ) on gut microbiota and the antibiotic resistome of a soil collembolan. Environ. Sci. Technol. 2019, 53 (21), 12823-12834.

(71) Stehlikova, Z.; Kostovcik, M.; Kostovcikova, K.; Kverka, M.; Juzlova, K.; Rob, F.; Hercogova, J.; Bohac, P.; Pinto, Y.; Uzan, A.; Koren, O.; Tlaskalova-Hogenova, H.; Zakostelska, Z. J. Dysbiosis of skin microbiota in psoriatic patients: Co-occurrence of fungal and bacterial communities. Front. Microbiol. 2019, 10, 438.

(72) Yao, Z.; Ma, Q.; Cai, Z.; Raza, M. F.; Bai, S.; Wang, Y.; Zhang, P.; Ma, H.; Zhang, H. Similar shift patterns in gut bacterial and fungal communities across the life stages of Bactrocera minax larvae from two field populations. Front. Microbiol. 2019, 10, 2262.

(73) Griffiths, S. M.; Galambao, M.; Rowntree, J. K.; Goodhead, I.; Hall, J.; O’Brien, D.; Atkinson, N.; Antwis, R. E. Complex associations between cross-kingdom microbial endophytes and host genotype in ash dieback disease dynamics. J. Ecol. 2020, 108 (1), 291-309. 